See discussions, stats, and author profiles for this publication at: https://www.researchgate.net/publication/321258805

The evolution of returns to education in the Middle East and North Africa: Evidence from comparable education policy changes in Tunisia

Article in Economics of Education Review · November 2017

Dol: 10.1016/j.econedurev.2017.11.008

CITATION

1

1 author:

Miquel Pellicer

University of Duisburg-Essen

23 PUBLICATIONS 132 CITATIONS

SEE PROFILE

Some of the authors of this publication are also working on these related projects:

Project Inequality in South Africa View project

Project Islamist Parties View project
READS

87 


\title{
The evolution of returns to education in the Middle East and North Africa: Evidence from comparable education policy changes in Tunisia*
}

\author{
Miquel Pellicer \\ University of Duisburg-Essen and University College Dublin
}

November 9, 2017

\begin{abstract}
Returns to education in the Middle East and North Africa (MENA) region are thought to have decreased in recent decades leading to youth frustration and political mobilization. Existing estimates of the evolution of education returns in the region have not had a causal focus and observed patterns may be driven by changes in selection bias as educational attainment expanded from a privileged few to large masses of the population. This paper exploits three comparable education policy changes over more than two decades in Tunisia to estimate the effect of education on public sector employment for different cohorts born from the 1950s to the 1970s. I combine census and labor force surveys from 2004 to 2010 amounting to more than one million observations of relevant cohorts. I find that returns have decreased across cohorts by around $1 / 3$ although they remain large even for the later cohorts.
\end{abstract}

${ }^{*}$ I would like to thank Eva Wegner, Tuomas Pekkarinen, Caroline Krafft and Ragui Assaad for useful comments on previous drafts. All errors are mine. Contact information: Miquel Pellicer, Geary Institute, UCD. Email: pellicer.miquel@gmail.com 


\section{Introduction}

There is increasing interest in understanding returns to education in developing countries. Two recent studies provide homogeneous estimates of returns to education in many different countries around the world (Montenegro and Patrinos (2014), Peet, Fink, and Fawzi (2015)). These studies find that, on average, returns to education tend to be similar (Peet et al. (2015)) or rather higher (Montenegro and Patrinos (2014)) in developing than in developed countries. Both studies find that returns to education in developing countries appear to have generally decreased over recent decades. These results can be interpreted, as do Montenegro and Patrinos (2014), as providing evidence that prices for skills track differences in supply: as human capital becomes less scarce (in developing countries relative to developed ones, and over recent decades) its reward falls.

However, since these estimates do not have a causal focus, another simple explanation is possible, notably, that the estimated differences across regions and over time could be due to differences in selection bias rather than differences in genuine education returns. When educational attainment is relatively low, the few obtaining high levels of education might be from a particularly privileged background, leading to strong selection bias. As educational attainment increases, the pool of educated individuals becomes less privileged and selection bias ought to become lower. There are several articles that have estimated causal returns to education in developing countries using school expansions or education reforms (see for instance, Duflo et al. (2001), Fang, Eggleston, Rizzo, Rozelle, and Zeckhauser (2012), Ozier (2016) and Aydemir and Kirdar (2017)). But estimates are still too few and differ too widely between studies to infer general conclusions. Moreover, no study has to the best of my knowledge explored the evolution of returns to education over time with a causal focus. More causal evidence is needed to understand returns to education in developing countries.

The importance of understanding returns to education and their change over time is particularly clear for the Middle east and North Africa (MENA) region. Returns to education feature prominently in explanations of the 2011 "Arab Uprisings" as well as in the successful popular religious Is- 
lamist mobilization in the region during recent decades. Such political mobilization is often attributed to the frustration engendered by the decrease in education returns in the region (see Goldstone (2011), Sanborn and Thyne (2014), Assaad (2014) for the "Arab Uprisigins" and Binzel and Carvalho (2016) for Islamist mobilization). Indeed, returns to education in the MENA appear to be lower than in other regions (Montenegro and Patrinos (2014)); unemployment rates of secondary/ university graduates in the MENA appear to be relatively high (Assaad (2014) and Campante and Chor (2012)); and individuals with higher education have tended to have less desirable jobs across cohorts (Binzel and Carvalho (2016)). These estimates, however, not attempting to be causal, suffer from the problem mentioned above. Educational attainment has expanded dramatically in the MENA in recent decades and the decreasing selectivity of education, rather than returns to education per se, may explain why the association between education and labor market outcomes has worsen over time to become one of the lowest in developing countries. Failure to obtain privileged jobs by recently educated middle classes need not generate frustration if in the past only a small highly educated privileged minority obtained privileged jobs because of their background.

This paper investigates returns to education in Tunisia and their change over last decades with a causal focus. To obtain estimates purged from potential selection biases I identify the effect of education using a quite unique set of three policy changes in Tunisia from the 1970s, 1980s and 1990s. All these three policy changes affected the transition from primary to secondary school. During the 1960s, promotion rates from primary school to secondary school in Tunisia were around 40\%, declined suddenly to around $25 \%$ in 1971, and were brought back to around $40 \%$ in 1980; in 1992, amid concerns that children were leaving education too early, promotion rates again increased, this time in a more gradual manner. The uniqueness of this set of policy changes lies in the fact that these changes span more than two decades while remaining comparable, and thus can be used to identify and compare the effect of education for different generations.

The data for the analysis come from the 2004 census as well as the 20052010 waves of the Tunisian Labor Force Survey. These are large data sets, with 300,000 to 600,000 individual observations in each labor force survey 
and around 2 million observations in the census. The different data sets are highly consistent, having been conducted at the same time of the year and using the same questions. I restrict the analysis to men, in order to abstract from the complex issues related to female labor force participation and female public sector employment in the region. The availability of 7 years of data allows me to control for age in a flexible way. In particular, all my regressions use year and age fixed effects.

The 1971 and 1980 changes (used in previous work in Pekkarinen and Pellicer (2013)) are analyzed using a fuzzy regression discontinuity design, while the 1992 change, being more gradual, is well suited for a regression kink approach. I conduct the analysis of the three policy adjustments separately. The first stage shows that all the discontinuities employed had strong effects on education. The jumps in 1971 and 1980 lead to a change of around 1 grade completed. The 1992 kink increased the educational attainment of around 0.2 grades completed per year born after the kink.

I focus on returns in terms of "good quality" jobs, particularly public sector employment, for my data does not contain information on wages. Public sector employment is consistently ranked highest among employment types by MENA youth for its benefits and prestige (see Assaad (2014) and Groh, McKenzie, Shammout, and Vishwanath (2014)). Moreover, accounts of youth political mobilization in the MENA single out the fall in returns to education in terms of public sector employment as origin of youth frustration (Assaad (2014), Binzel and Carvalho (2016)). Using public sector employment as main outcome also reduces the concern of conflating cohort and age effects in my estimates. Since I observe all cohorts essentially at the same, early cohorts are observed when old and late cohorts are observed when young. I provide suggestive evidence that, for public sector employment, age effects are relatively unimportant for the ages at which my effects are estimated.

I find evidence of a decrease in the returns to education in terms of good jobs. My estimates suggest a decline of around 1/3 between cohorts born in the 1950s and those born in the 1970s. However, in spite of this, I find that education still increases substantially the chances of obtaining public sector jobs even for youth. My preferred estimates imply that one more year of education increases the chance of public sector employment 
by $4 \mathrm{pp}$ for the younger cohorts. In a context where around $19 \%$ of males in my sample hold a public sector job, this figure is still quite large.

The paper is organized as follows. Section 2 explains the educational policy changes in Tunisia that I use to identify the effect of education. Sections 3 and 4 present the data and the empirical approach, respectively. Section 5 shows the results and section 6 discusses them and concludes.

\section{Access to secondary school in Tunisia}

Since independence in 1956, education has been a key concern for the Tunisian government. The government has sought to affect enrollment rates in different ways at different points in time. One of these ways has been to regulate access to secondary school. Until the 1990s, there was a nation-wide examination at the end of the last year of primary school (6th grade) regulating access to secondary school.

There is some evidence that thresholds for passing such exam were politically manipulated in order to follow specific policy objectives. For instance, a meeting at the Education Ministry stated quite explicitly that "We have admitted [to secondary school] only the candidates having passed the threshold except in the disadvantaged provinces, where, as a political option, it was decided to lower the threshold to 9.6 [from the 'theoretical' threshold of 10]", (Ministère de l'Education Nationale, 1974). In some years, this manipulation of access to secondary school has been very severe, leading to substantial changes in educational attainment of specific cohorts. These "policy changes" (or "policy adjustments") form the basis for the instruments for educational attainment in this paper. Pekkarinen and Pellicer (2013) discuss two such adjustments occurring during the 1970s. This paper adds to these another one from the 1990s.

\subsection{Policy changes in the 1970s}

Figure 1 shows the evolution of promotion rates from the last year of primary school into secondary school. After many years with promotion rates of around 40\%, ever increasing school enrollments and investments in education generated budgetary pressures that induced the government to dras- 
tically reduce access to secondary school. In 1971, thus, promotion rates fell to around $25 \%$.

During the 1970s, however it became apparent that the reduction in promotion rates was problematic. The school system at the time consisted of 6 years of primary school and 7 years of secondary. It was considered that too many students were dropping out of the school system too young, after only 6 years of education. Promotion rates, thus suddenly jumped back up in 1980, again to around $40 \%$.

Pekkarinen and Pellicer (2013) show that these changes in promotion rates had a strong impact on educational attainment of men. In particular, cohorts exposed to the low access policy regime of the 1970s obtain on average around 1 less year of education and are around 10pp less likely to attain secondary or university education.

\subsection{Policy changes in the 1990s}

Even if promotion rates had somewhat increased during the 1980s, concerns remained about children dropping out of the schooling system too early. A World Bank loan report (World Bank (1989)) describes in detail the situation as viewed at the time and the proposed solutions. Most importantly, a major policy reform was planned that consolidated primary school and the first three years of secondary school into a single cycle to be called "basic education". The reform was signed into law in 1991.

Given that the biggest bottleneck at the time in the first years of education system was grade 6 , the reform explicitly set targets for promotion rates from grade 6 to grade 7 , starting in 1992 (from $45 \%$ to $70 \%$ by 1995) (World Bank (1989)). An important difference relative to the policy changes of the 1970s, however, is that the change was to be somewhat more gradual, possibly to prevent a sudden overflow of classes at the upper basic level. Indeed, World Bank (1989) states as planned benefits of the reform "an increase in the number of students enrolled in upper basic education of 123,000 over the 1992-96 Plan and 152,000 over the 1997-2001 Plan" (p. ii).

The evolution of promotion rates in figure 1 is consistent with these plans. In particular, we observe a sudden increase in these rates in 1992, 
after which promotion rates continue to increase. In 2001, having reached promotion rates of almost $90 \%$, the increasing trend stops.

In the analysis that follows, all these different sudden changes in promotion rates will be used as separate instruments for secondary/ university education affecting different cohorts. The changes in 1971 and 1980 correspond to a one-off jump and so will be exploited using a regression fuzzy discontinuity design. The change in 1992 continues in later years and will be analyzed using a regression kink approach. As will be shown below, taking into account the effects of grade repetition, these approaches fit the evolution of male educational attainment remarkably well.

It is important to note that the three "policy adjustments" considered are quite comparable as they all affect promotion rates out of grade 6 of primary school. The fact that the 1992 change was part of the larger reform establishing "basic education" could be a concern as the larger reform not only affected promotion rates but possibly the whole educational system. However, in the analysis below this turns out not to matter much. "Basic education" started in 1989 so that the first cohort turning 6 and being fully exposed to it was born in 1983. The increase in promotion rate occurred in 1992, before this cohort reached 6th grade, and thus applied to cohorts still in the old primary-secondary system. As it happens, I use in the analysis below of the 1992 kink cohorts born no later than 1983 and so the effect identified does not incorporate the role of the establishment of "basic education". Rather, the reform used concerns simply an increase in promotion rates from the old primary to the old secondary levels, as the other policy changes so that the three policy changes ought to be indeed comparable.

\section{Data}

\subsection{Data sources}

The data for the analysis come from the 2004 census and the 2005-2010 waves of the Tunisian Labor Force Survey (LFS). Sample sizes are large: my version of the census data includes around 2 million observations (one quarter of the Tunisian population) and the LFSs have sample sizes ranging 
from around 300,000 per wave in 2005 and 2006, to around 600,000 per wave in the years 2007 to $2010 .{ }^{1}$ All surveys provide weights to recover the representativity of the sample, and I use these weights throughout the analysis.

All data sources include information on age, education, employment, as well as job characteristics, such as employment status (employer, employee, independent, etc.) or place of employment (public sector, etc.) Education is coded in four levels: no education, primary, secondary and university. Primary/ secondary is always coded under the "old regime" of 6 years of primary and 7 of secondary. Secondary education includes vocational training.

All datasets have a high degree of consistency. They all have used the same questionnaire and have been undertaken at the same time (from March to June of the respective year). Data post-collection processing has also been harmonized by the Tunisian National Institute of Statistics (INS).

For the analysis below, I code employment-related variables as dummy variables with value zero if the category is not fulfilled (instead of missing). Thus, public sector employment is coded zero even if the person is inactive.

While all surveys have pre-processed information on education levels there is generally no information on actual grades (i.e. years) completed. Since such a variable turns out to be useful for the analysis, I construct an approximation of this with the available information. In particular, the 2010 LFS does have information on grades completed and from this I compute the average grades completed at each education level (primary, secondary and university attainment). ${ }^{2}$ With this information, I construct a variable for all survey years, denoted "approximate grades completed", that attributes to each education level its corresponding average grades completed.

\footnotetext{
${ }^{1}$ All these data are freely available online at http://www.ins.nat.tn/indexfr.php

${ }^{2}$ I do this for the cohorts affected by each of the policy changes and the figures happen to be very similar for the different cohorts. These are 0 for no education, .7 for primary, 10.3 for secondary and 16.5 for university.
} 


\subsection{Summary statistics}

Table 1 shows the summary statistics of the key variables in the different samples used in the analysis. The different subsamples correspond to windows around the different jumps or kinks in birth year that I exploit as instruments for education, as well as the full sample including all these windows. Each subsample, thus, corresponds to different birth cohorts and ages. For each subsample, the mean of the variables are shown. The values in the table are sensible, giving some confidence in the data to be used. These show, for instance, the steady increase in educational attainment and the apparent decline in public sector employment over cohorts.

A data quality issue to mention which is potentially relevant for identification is age heaping (see Barreca, Guldi, Lindo, and Waddell (2010)). As expected, inspection of age distributions shows clear evidence of age heaping. I thus follow Barreca et al. (2010) and perform the analyses without the bunched age and birth year values. ${ }^{3}$ In any case, the issue is not critical to our results: (unreported) regressions show that while estimates are somewhat less similar across specifications when using the raw data, this does not affect results substantively.

\section{Empirical Approach}

The empirical approach in this paper exploits the education policy changes of the 1970s, 80s and 90s to identify the effect of education on public sector employment. Following the literature, I aggregate the data into cells given by survey year and birth cohort (ex. Oreopoulos (2006) or Hungerman (2014)). I consider a "grouped probability model" such as:

$$
\pi_{a c t}=\alpha_{0 t}+\gamma_{0 a}+h_{0}(c)+\beta E_{a c t}+u_{a c t}
$$

where $a$ indexes age, $c$ indexes cohort (i.e. year of birth) and $t$ indexes time (i.e. survey year). $\pi$ refers to the probability associated to the outcome variable public sector employment, and $u$ denotes an error term. $\alpha_{0 t}$ and $\gamma_{0 a}$ are time and age fixed effects, respectively, while $h_{0}$ is a potentially

\footnotetext{
${ }^{3}$ In particular, I compute, by survey year, the age cells with more than $10 \%$ more counts than the average of the preceding and following age cells, and erase these.
} 
non-linear function of birth cohort. $E$ denotes education, in particular attainment of secondary/ university or approximate grades completed, and thus $\beta$ is the parameter of interest.

\subsection{Instruments}

Because of the possible endogeneity of education, I instrument education with exposure to the different policy changes above. In particular, I consider three instruments: the jump in promotion rates to 7 th grade in 1971 and in 1980, and the (gradual) increase in these rates from 1992 onward. To the best of my knowledge, these changes were not announced, implying that students would not have been able to act strategically to benefit from (or protect themselves against) changes promotion rates. ${ }^{4}$

The first two instruments, exposure to the 1971 and the 1980 jump in promotion rates, are essentially step functions of the birth cohort. If all students started schooling at age six and there was no grade repetition, children born after 1959 (1968) would have faced low (high) promotion rates and vice-versa. In reality, earlier cohorts also get some exposure to the policy change because of grade repetition. I use the cohort distribution of grade 6 boys in 1967 and 1982 to determine exposure of earlier cohorts to the policy changes in 1971 and 1980, respectively (see Ministère de l'Education Nationale (1967) and Ministère de l'Education Nationale (1983)). These distributions imply that only a small minority of boys were 12 years old in grade 6 ( $25 \%$ in 1982 and $10 \%$ in 1967). ${ }^{5}$ The instruments used for exposure to the 1980 and 1971 policy changes are thus step functions, except that instead of an abrupt zero-one change at a given birth year, the step is divided between several cohorts. Identification using these instruments is essentially as in a fuzzy regression discontinuity design.

The first stage using these instruments (denoted by $D_{1 c}$ ) is:

\footnotetext{
${ }^{4}$ In the course of the research for this project, I conducted interviews with a former education minister (active for 2 years in the mid 1990s), with a senior academic with expertise on education in Tunisia, as well as enquired with people of the relevant cohorts about the policy changes. Only the ex-minister of education was familiar with the idea that promotion rates were manipulated in order to regulate the supply of secondary school students. All other informants did not know about these policy changes.

${ }^{5}$ The exact figures I use are, for 1980: 0.02 born in 1964, 0.16 in 1965, 0.27 in 1966, 0.29 in 1967, 0.22 in 1968 and 0.04 in 1969. For 1971, these are 0.21 born in 1955, 0.25 in 1956, 0.24 in 1957, 0.18 in 1958, 0.1 in 1959 and 0.02 in 1960.
} 


$$
E_{a c t}=\alpha_{1 t}+\gamma_{1 a}+h_{1}(c)+\rho_{1} D_{1 c}+u_{a c t}
$$

with $\rho_{1}$ being the first stage coefficient.

The second type of instrument used is a kink function of the birth cohort. As mentioned above, promotion rates jumped upward in 1992 and increased thereafter until 2001. Absent grade repetition, educational attainment would follow exactly the same pattern: an initial jump followed by a gradual increase. However, grade repetition distributes the initial jump into several earlier cohorts and this in effect implies that the resulting pattern can be well approximated by a kink. Using again the 1982 cohort distribution of grade 6, the kink is estimated to start at the 1976 cohort. The first stage using the kinked instrument is:

$$
E_{a c t}=\alpha_{2 t}+\gamma_{2 a}+h_{2}(c)+\rho_{2} c D_{2 c}+u_{a c t}
$$

where $D_{2 c}$ equals 1 for cohorts born after 1976 and zero otherwise, and birth cohort $c$ is centered at 1976. The first stage coefficient using the kink instrument is $\rho_{2}$.

Figure 2 illustrates the suitability of these instruments. The figure shows secondary or university attainment (i.e. achievement of more than grade 6 of primary schooling) for different birth cohorts. A solid line shows the fitted values of a regression such as 2 and 3, only that in this case, the whole sample is considered and all instruments are included together with a 2nd degree polynomial on birth year. The fit is remarkably good. The figure clearly shows first a downward and then an upward shift from the 1971 and 1980 jumps. As just mentioned, the downward and upward shifts are distributed over several cohorts due to grade repetition and this can obscure the jumps. To make the jumps visually clearer, the figure also adds a dashed line that removes the smoothing of the instruments from grade repetition. This is a fitted regression that replaces the 1971 and the 1980 instruments by indicator functions with value one for cohorts above the cohort most exposed to the policy shift. ${ }^{6}$ The jumps in educational

\footnotetext{
${ }^{6}$ In particular, the variable has value one for cohorts above the modal cohort among those exposed to the policy shift; for instance, for the 1971 jump, this is the cohort born in 1956.
} 
attainment following the 1971 and 1980 jumps are thus very clear.

Regarding the post-1992 policy adjustment, a kink starting in 1976 is apparent. It appears that modeling the effect of this policy change as a kink in educational attainment is a good approximation. ${ }^{7}$

\subsection{Polynomial and window specifications}

When implementing regression discontinuity or regression kink designs, bandwidths and polynomial degrees need to be chosen. My choices of bandwidth are somewhat restricted by the discontinuities in other parts of the distribution. In particular, there are 7 or 8 birth years between the discontinuities I exploit: i.e. from 1969, the last cohort affected directly by the 1980 jump, and 1976, the first cohort affected by the kink (and similarly for the 1971 and the 1980 jumps). ${ }^{8}$

Given this constraint, my choice of specifications is rather pragmatic. I consider two specifications, one quadratic with the maximum sensible window (7 years) and one linear with small window (4 years). For the 1992 kink, the quadratic specification follows the common practice of interacting the second degree polynomial with the indicator function $D_{2 c}$. For the 1971 and 1980 jumps, all specifications allow for the slope to be different before and after the jump. Given the lack of certainty regarding the best specification to use in regression kink designs reported in Card, Lee, Pei, and Weber (2016), I present in the on-line appendix results for all different bandwidths between 4 and 7 for both the linear and the quadratic specification. The specification I will use as benchmark is the linear one with the smallest (4 year) window. Finally, all standard errors are clustered at the

\footnotetext{
${ }^{7}$ The use of a regression kink approach in this setting is somewhat unusual. Typically, analyses using this approach have exploited explicitly kinked allocation rules (see, for instance Card, Lee, Pei, and Weber (2012) or Dobbie and Skiba (2013)). In my case, there is no explicitly kinked allocation rule. Still, the policy change (the sudden increase in promotion rates in 1992) does generate a kink owing to a non-degenerate distribution of cohorts exposed to this jump, as shown in figure 2. Another point to note regarding the use of regression kink design in this context is that, contrary to other settings, the running variable here (birth year) is hardly manipulable. Therefore, the assumptions that enable a causal interpretation of the regression kink estimates are more likely to hold than in other settings (ex. where the running variable is income, see Jones (2013) or Card et al. (2012)).

${ }^{8}$ The first cohort affected substantially by 1980 jump was born in 1965 while the 1971 jump ends precisely at cohort born in 1958
} 
birth year level.

\subsection{Life cycle concerns}

Comparing returns to education for different cohorts at the same time conflates cohort effects and age effects. Ideally, to solve this issues, one would want to observe different cohorts at the same age. In my case, this is not possible. The regression discontinuity and kink approaches identify the effect of education for the specific age at which the jump/ kink takes place. The 1992 kink identifies the effect for individuals born in 1976, which at the time the surveys took place were in their late 20s/ early 30s. For the 1971 jump, effects are identified for individuals born around 1956, which at the time the surveys took place were in their late 40s/ early 50 s.

How much of a problem this is depends on the life-cycle pattern of returns. A recent study on the life-cycle return to education in Norway using wages as outcome (Bhuller, Mogstad, and Salvanes (in press)) shows that returns to education appear upward sloping up until the age of 50 . Attributing differences in returns at age 50 and age 30 to cohort effects could be highly misleading. In my case, the outcome is public sector employment, and this is likely to have a flatter life-cycle profile than wages: public employees are likely to have reached the public sector before age 50 and to keep working there thereafter, even as their wages continue increasing. Figure A1 in the online appendix provides evidence on this issue, showing age profiles of public sector employment as well as the age profile of OLS-based returns to education in terms of public sector employment. The figure indicates rapid increases in these until age 30; a slow down to peak at 35; and stability until the mid 50s. This suggests that life cycle considerations are not very problematic when comparing public sector employment for cohorts observed in the early 30s with cohorts observed up to the early $50 \mathrm{~s}$.

Using all surveys, the mean age (weighted by cell size) of individuals born in 1976 is 29 and the mean age of individuals born in 1956 is 49.2. At 29 , returns still seem to increase rather rapidly so it seems appropriate to observe such youth at a slightly older age. To do so I also run the analysis considering only the later years, from 2007 to 2010. This allows me to 
bring the identified age of the 1976 cohort to 31.2 while still allowing me to control for a full set of age dummies. The mean age for the older cohort in turn becomes 51.4. ${ }^{9}$

\section{Results}

\subsection{First stage results}

Table 2 shows the first stage for the different instruments and different possible endogenous variables. Each column corresponds to a different specification in terms of polynomial/ window and waves used, and each row panel corresponds to a different instrument: the 1971 and 1980 jumps, and the 1992 kink. I consider as first potential endogenous variable attainment of secondary or university. This is the "natural" endogenous variable of the analysis, since this is the margin affected by the instruments used.

As expected from the figure above, all instruments are quite strong. Attainment of secondary or university decreases by around $18 \mathrm{pp}$ and rebounds around $8 \mathrm{pp}$ from the reduction and subsequent recuperation of promotion rates in 1971 and 1980, respectively. The 1992 kink increases the slope of this education variable by around $2 \mathrm{pp}$. This number is quite large, implying that cohorts 5 years after the kink experienced 10 pp more attainment of secondary/ university than if the kink had not happened.

The table also shows that estimates are quite similar across specifications. This strengthens the confidence on the different instruments, particularly the 1992 kink which is somewhat heterodox: the kink appears to be present with a window of 4 years as well as when using the 2nd degree polynomial at either side of the kink. All estimates are also similar when considering the restricted 2007-2010 sample.

While attainment of secondary or university education might be the most natural instrument in our setting, it may not be the most appropriate for our purposes. The reason is that we want to compare the effect of different policy changes. While all policy changes affected the primary/

\footnotetext{
${ }^{9} \mathrm{On}$ the basis of figure $\mathrm{A} 1$ in the on-line appendix, the difference in returns attributable to age effects when comparing the 1976 and 1956 cohort would then be fairly small, of 0.005 .
} 
secondary margin, it may still be the case that they induced a different share of children to reach university. This would then render comparison between instruments misleading. The second row in each panel of table 2 shows the effect of the instruments on attainment of university. As expected, these coefficients are lower than those for secondary/university. For the $1992 \mathrm{kink}$, around 40\% of those progressing beyond primary because of the instrument made it to university. This share is smaller for earlier policy changes, the 1980 jump (35\%), and particularly the 1971 jump (13\%).

Given these differences in the mix of secondary/ university attainment induced by the different policy changes, I use approximate grades completed as endogenous variable in the analysis. The third row in each panel shows the first stage results for this variable. According to this variable, the 1992 kink increased the attainment by around 0.2 grades completed per year born after the kink, whereas the 1980 and 1971 jumps lead to around 0.75 more and 1.2 fewer years of education, respectively. Overall, it is clear that all the policy changes I consider had an economically significant effect on educational attainment.

\subsection{Effect of education on public employment for dif- ferent cohorts}

\section{Reduced form results}

Table 3 presents the reduced form results. As before, columns represent different specifications, while rows refer to the analysis using different instruments and outcome variables. The first row panel uses public sector employment as outcome variable, the main outcome of interest. The pattern shown in the table is very robust: Using all instruments and in all specifications, cohorts exposed to better promotion rates show higher public sector employment. Possibly the most noticeable result in the table is that the positive effect of education on public sector employment is apparent even for younger cohorts. Figure A2 in the on-line appendix presents the graphical counterpart of the reduced form estimates, and illustrates clearly the effect of all three policy changes on public sector employment. 


\section{IV results}

While it appears clear that education increases the chances of obtaining public sector employment, even for younger cohorts, the question of interest is whether such returns have decreased across cohorts. In order to address this question, table 4 shows the corresponding OLS/ IV results. Again, we focus on the first row panel that uses public sector employment as outcome variable.

The first insight from the IV estimates is that estimated effects are very large. Coefficients range from 0.025 to 0.07 , implying that an increase in, say, 4 years of education improves the chances of obtaining public sector employment by between 10pp and 28pp.

The second, and possibly most important insight, is that effects appear consistently larger for the oldest cohort, the one born in the 1950s, and reaching the labor market in the 1970s. Whereas comparisons between the youngest and middle cohorts are inconclusive and depend on the specification, comparisons between the youngest and oldest cohorts are consistent. The last rows of the panel present the difference in coefficients between these cohorts and the p-value of this difference. The difference is around 2$3 \mathrm{pp}$, and is statistically significant at conventional levels. The magnitude is also economically significant, a $1 / 3$ decrease, providing evidence that indeed returns to education in terms of public sector employment have declined noticeably across cohorts.

\subsection{Robustness}

\section{Life-cycle effects}

I consider several robustness checks of the main results of the paper. First, I consider whether results are driven by life cycle effects. The last column of tables 3 and 4 present the reduced form and IV results using the 2007-2010 sample, where effects are identified for older youth, aged 31.2. Coefficients for the 1992 kink do not go up when identifying the effect for older individuals. Actually, coefficients are very similar to those estimated with the sample of all years. Reassuringly, the same applies to the coefficients for the oldest cohorts, and this implies that the difference between 
the two remains similar, as shown in the last rows of the panel of table 4 . It appears that life-cycle effects are not driving the difference in returns for the different cohorts.

\section{Other types of "good jobs"}

I also consider the robustness of my results to "good jobs" other than public sector employment. While public sector jobs are the paradigmatic example of a good job in the MENA region, there are other measures of good jobs that can be used, most notably jobs associated to high levels of skill. As an alternative measure of desirable jobs I consider jobs as professional or technician: categories 2 and 3 of the ILO ISCO-08 classification. These jobs are categorized by the ILO as having the highest levels of skill. ${ }^{10}$

The second row panel of tables 3 and 4 show the corresponding results for high skill occupations. It is worth noting that this variable is only present for 2004, 2009 and 2010, so that estimates are somewhat less reliable. Nevertheless, the pattern in the table is fairly clear: while for the oldest cohort the effects of education on skilled jobs is clear and relatively high, for the youngest cohort effects are fairly small. The difference in effect between the youngest and oldest cohort is of around 2pp. and is statistically significant. Education appears to have reduced opportunities to obtain good jobs even beyond the public sector. ${ }^{11}$

It is also interesting to note the direction of the OLS biases: whereas OLS estimates tend to be larger than IV estimates when it comes to skilled occupations, the reverse holds true for public sector occupations. This suggests that ability bias may be relevant for skilled occupations, but not so much for public sector employment.

\section{Potential Confounders}

I also consider the possibility that my results may be driven by confounders; i.e. shocks or policy changes relevant for public sector employment simulta-

\footnotetext{
${ }^{10}$ I exclude category 1 of managerial jobs. These jobs, while also requiring high levels of skill, have a strong age gradient which would confound the comparison between younger and older cohorts.

${ }^{11}$ I do not attempt to carry out the estimation for the high skill job variable when restricting the sample to the 2007-2010. The reason is that, since this variable is not available in several survey years, I cannot control for age in a sufficiently flexible way.
} 
neous with the policy changes used as instrument. While it is not possible to verify explicitly for all these, there are reasons that alleviate these concerns in this case. Most notably, it is unlikely that macro factors affecting the economy or the political system at a given point in time counfound my results. The reason is that the effects identified are cohort effects. Changes occurring during a given year, say a policy retrenching public sector employment, would affect many different cohorts entering the labor market at that moment: those just finishing university, those finishing secondary school and not continuing, younger cohorts not having repeated any course, older cohorts having started later or having repeated, etc. The effect of such policy would thus be severely diluted across several cohorts rendering it very unlikely to generate the results observed. The counfounders potentially relevant are those that generate variation at the cohort level. However, the size of the education effects we observe are so large that it seems unlikely that cohort effects unrelated to education policy have labor market implications comparable to these.

Regarding education policy, to the best of my knowledge, no substantial policy occurred simultaneously with the ones considered here. The fact that the policy changes I use are only "adjustments", and not large policy reforms reduces the chances that other components of education policy changed at the same time. There are however two potential confounders emerging from the very policy changes I use as instruments. First, the expansion and reductions in enrollment generated by the change in promotion rates would have had implications for class size, and this could affect learning and future labor market outcomes. This could bias results towards zero because the change in learning would go in the opposite direction as the change in educational attainment of the cohort. For instance, the 1971 retrenchment would lead to small class that would improve the outcomes of the affected cohorts, partly compensating the impact of the reduction in educational attainment. This is, however, a second order effect and unlikely to lead to a very large bias relative to the size of the effects estimated. Moreover, this potential bias should not affect very much comparisons between different policy changes, since all biases would be attenuating.

Another potential confounder emerging from the policy changes used as instruments comes from the first policy adjustment in 1971, which may 
have had some effects on other cohorts. There is some evidence the 1971 restrictions on access to secondary school were accompanied by restrictions to access to primary school. ${ }^{12}$ This would have affected cohorts born around 1964, close to the cohorts affected by the 1980 policy adjustment. This, in turn, could generate discontinuities in access to primary school that confound the effect of the 1980 policy change. ${ }^{13}$

To check this, I perform a "placebo" first stage on the share of cohorts with no formal education. Results are in table A1 in the on-line appendix. Ideally, such placebo exercise would deliver insignificant results, for the instruments used affected access to secondary school and ought to have left the share of people with no formal education unchanged. This is indeed largely the case for the the 1971 and 1992 policy changes. However, for the reasons just exposed, the 1980 policy change does show some effect, although such effect is relatively small. In any case, this confounder has no impact on the main results of the paper. Table A2 in the on-line appendix re-estimates the IV regressions adding the share of people with no education as an additional control. Qualitatively, results remain unchanged. Results are very similar for the 1971 and 1992 policy changes while coefficients for the 1980 change become slightly higher. If at all, results are neater with this specification, since the decline in returns estimated is more gradual, from around 0.7 to 0.55 and then to 0.4 for the 1971, 1980 and 1992 policy changes, respectively.

\section{Different Windows and Weights}

Finally, I consider robustness to different windows and to the absence of survey weights. Table A3 in the on-line appendix show the results allowing for windows between 4 and 7 for both, the linear and the quadratic specifications. Results are substantively the same across specifications. For the 1976 cohort, returns tend to be between 0.03 to 0.04, whereas for the 1956 cohort returns are estimated between 0.05 and 0.07 . In all cases, returns are higher for the older cohort, although they remain substantial for the

\footnotetext{
${ }^{12}$ Tibi (1974) notes that after a growth of $9 \%$ per annum in new students admitted to the first year of primary school, numbers actually declined in 1970 and 1971, to then pick up again.

${ }^{13}$ This argument applies only to the 1971 policy change because it is the only one that entailed a reduction that could be implemented rapidly.
} 
younger one.

As regards the role of survey weights, table A4 in the on-line appendix shows that results without these weights are almost identical than the benchmark results.

\section{Discussion and Concluding Remarks}

This paper has sought to estimate the evolution of returns to education in the MENA over several decades. Comparable education policy changes spanning more than 20 years in Tunisia enable me to provide such causal estimates. My results show that rewards of education in terms of high quality jobs have declined between cohorts born in the 1950s and those born in the 1970s, although even for the latter they remain substantial.

Although returns to education are estimated at different ages for different cohorts, the life-cycle profile of public sector employment implies that returns estimated for the different ages at which my estimates refer to are relatively comparable. If at all, returns to education for youth may be slightly underestimated, implying that returns to education may have dropped slightly less. Another important caveat is that, while the policy adjustments used as instrument are comparable, the compliers of each (i.e. the individuals induced to obtain more or less education because of the policy adjustment) may be different. Since my IV estimates are Local Average Treatment Effects (LATE) for compliers, differences in the IV estimates across cohorts may partly reflect heterogenous treatment effects for the different complier populations. It can be argued, however, that the effects for such complier populations are interesting in their own right. Being the individuals at the margin of accessing secondary education, they are possibly the most relevant ones when considering policy actions to regulate educational attainment.

My results are consistent with existing non-causal evidence linking education and labor market outcomes in the MENA, such as Binzel and Carvalho (2016), and confirm that such effects are indeed due to education per $s e$, and not to other unobserved factors correlated with education. Indeed, for public sector employment, IV estimates tend to be larger, not smaller, than OLS ones, possibly because the non-linearity of returns to educa- 
tion over grades (see Pekkarinen and Pellicer (2013) and Riddell and Song (2011)). Most importantly, the fall in education returns is larger for the IV estimates than for the OLS ones, although the drop is similar in relative terms (around 1/3). Thus, it appears that the reduction in returns from OLS-type of estimates is not due to decreasing selection bias associated to the rapid increase in educational attainment. One possible explanation for the lack of importance of selection bias could be the relevance of formal degrees for hiring, particularly in public sector, which renders irrelevant other attributes for obtaining good quality employment, as emphasized in Assaad (2014).

My results contribute to the small but growing literature on causal estimates of returns to education in the MENA region. Pekkarinen and Pellicer (2013), Aydemir and Kirdar (2017) and Assaad, Aydemir, Dayioglu Tayfur, and Kirdar (2016) focus on the education- labor market nexus in the MENA, whereas Lavy and Zablotsky (2015) and Gulesci and Meyersson (2014) focus specifically on female outcomes such as fertility and female religiosity, respectively. Pekkarinen and Pellicer (2013) find strong returns to education in terms of public employment for older cohorts in Tunisia, whereas Aydemir and Kirdar (2017) and Assaad et al. (2016) find low wage returns to education for youth in Turkey and Egypt, respectively. Assaad et al. (2016) moreover find no returns in terms of public sector employment. My estimates confirm the decline returns to education for public sector employment, but provide evidence that returns remain large even for youth. This disagreement between my estimates and those in Aydemir and Kirdar (2017) and Assaad et al. (2016) may come from the fact that they use as instrument changes in years of compulsory education. Such instrument estimates the returns to a year more or less of schooling, without incorporating the consequences of obtaining degrees, or the peer and network effects that follow from progressing to a new level of education. The instruments I use, in contrast, do incorporate these additional effects of education. The disagreement between my estimates and theirs thus suggests that education may affect labor market outcomes via peer effects, networks, or degrees, more than through pure human capital accumulation.

My estimates have implications for understanding the role of returns to education for political mobilization in MENA. In particular, the decline in 
returns in terms of public sector employment that I estimate is consistent with the commonly held narrative of increasing grievances and frustration of MENA youth. However, the fact that returns to education for youth remain large presents a puzzle to such accounts. The fall of returns I estimate, from 0.071 to 0.045 , does not appear dramatic enough to warrant such a strong buildup of grievances. This would be consistent with the recent analysis of education, grievances and political mobilization in Pellicer, Assaad, Krafft, and Salemi (2017), which suggests that education may have been relevant for the Arab Uprisings, not via grievances, but instead via decreasing the costs of mobilization.

\section{References}

Assaad, R. (2014). Making sense of arab labor markets: the enduring legacy of dualism. IZA Journal of Labor \& Development, 3(1), 1-25.

Assaad, R., Aydemir, A., Dayioglu Tayfur, M., \& Kirdar, M. (2016). Returns to Schooling in Egypt. ERF Working paper No. 1000.

Aydemir, A., \& Kirdar, M. G. (2017). Low wage returns to schooling in a developing country: Evidence from a major policy reform in turkey. Oxford Bulletin of Economics and Statistics.

Barreca, A. I., Guldi, M., Lindo, J. M., \& Waddell, G. R. (2010). Running and jumping variables in $r d$ designs: Evidence based on race, socioeconomic status, and birth weights (IZA Discussion Paper No. 5106).

Bhuller, M., Mogstad, M., \& Salvanes, K. G. (in press). Life cycle earnings, education premiums and internal rates of return. Journal of Labor Economics.

Binzel, C., \& Carvalho, J.-P. (2016). Education, social mobility, and religious movements: The islamic revival in egypt. The Economic Journal.

Campante, F. R., \& Chor, D. (2012). Why was the arab world poised for revolution? schooling, economic opportunities, and the arab spring. The Journal of Economic Perspectives, 167-187.

Card, D., Lee, D., Pei, Z., \& Weber, A. (2012). Nonlinear policy rules and the identification and estimation of causal effects in a generalized re- 
gression kink design (Working Paper). National Bureau of Economic Research.

Card, D., Lee, D. S., Pei, Z., \& Weber, A. (2016). Regression kink design: Theory and practice (Working Paper). National Bureau of Economic Research.

Dobbie, W., \& Skiba, P. M. (2013). Information asymmetries in consumer credit markets: Evidence from payday lending. American Economic Journal: Applied Economics, 5(4), 256-282.

Duflo, E., et al. (2001). Schooling and labor market consequences of school construction in indonesia: Evidence from an unusual policy experiment. American Economic Review, 91(4), 795-813.

Fang, H., Eggleston, K. N., Rizzo, J. A., Rozelle, S., \& Zeckhauser, R. J. (2012). The returns to education in china: Evidence from the 1986 compulsory education law (Working Paper). National Bureau of Economic Research.

Goldstone, J. A. (2011). Understanding the revolutions of 2011. Foreign Affairs, 90(3), 8-16.

Groh, M., McKenzie, D., Shammout, N., \& Vishwanath, T. (2014). Testing the importance of search frictions, matching, and reservation prestige through randomized experiments in jordan. World Bank Policy Research Working Paper(7030).

Gulesci, S., \& Meyersson, E. (2014). for the love of the republiceducation, secularism, and empowerment. working paper.

Hungerman, D. M. (2014). The effect of education on religion: Evidence from compulsory schooling laws. Journal of Economic Behavior \&6 Organization, 104, 52-63.

Jones, M. R. (2013). The eitc and labor supply: evidence from a regression kink design.

Lavy, V., \& Zablotsky, A. (2015). Women's schooling and fertility under low female labor force participation: Evidence from mobility restrictions in israel. Journal of Public Economics, 124, 105-121.

Ministère de l'Education Nationale. (1967). Enseignement primaire en chiffres, anne scolaire 1966-1967. Tunis: Ministère de l'Education Nationale.

Ministère de l'Education Nationale. (1974). Procès verbaux des reunions 
tenues 1974. Tunis: Ministère de l'Education Nationale.

Ministère de l'Education Nationale. (1983). Statistiques de l'enseignement primaire. Tunis: Ministère de l'Education Nationale.

Montenegro, C. E., \& Patrinos, H. (2014). Comparable estimates of returns to schooling around the world. Policy Research Working Paper Series.

Oreopoulos, P. (2006). Estimating average and local average treatment effects of education when compulsory schooling laws really matter. The American Economic Review, 96(1), 152-175.

Ozier, O. (2016). The impact of secondary schooling in kenya: A regression discontinuity analysis. Journal of Human Resources.

Peet, E. D., Fink, G., \& Fawzi, W. (2015). Returns to education in developing countries: Evidence from the living standards and measurement study surveys. Economics of Education Review, 49, 69-90.

Pekkarinen, T., \& Pellicer, M. (2013). Education and allocation of skills in tunisia: evidence from an education reform. IZA Journal of Labor E Development, 2(1), 1-21.

Pellicer, M., Assaad, R., Krafft, C., \& Salemi, C. (2017). Grievances or skills? the effect of education on youth attitudes and political participation in egypt and tunisia.

Riddell, W. C., \& Song, X. (2011). The impact of education on unemployment incidence and re-employment success: Evidence from the us labour market. Labour Economics, 18(4), 453-463.

Sanborn, H., \& Thyne, C. L. (2014). Learning democracy: Education and the fall of authoritarian regimes. British Journal of Political Science, $44(04), 773-797$.

Tibi, C. (1974). Développement économique et aspects financiers de la politique d'éducation en tunisie (Vol. 2). Paris: Presses de l'Unesco.

World Bank. (1989). Staff appraisal report, republic of tunisia, education and training sector loan (Tech. Rep.). Wolrd Bank. 


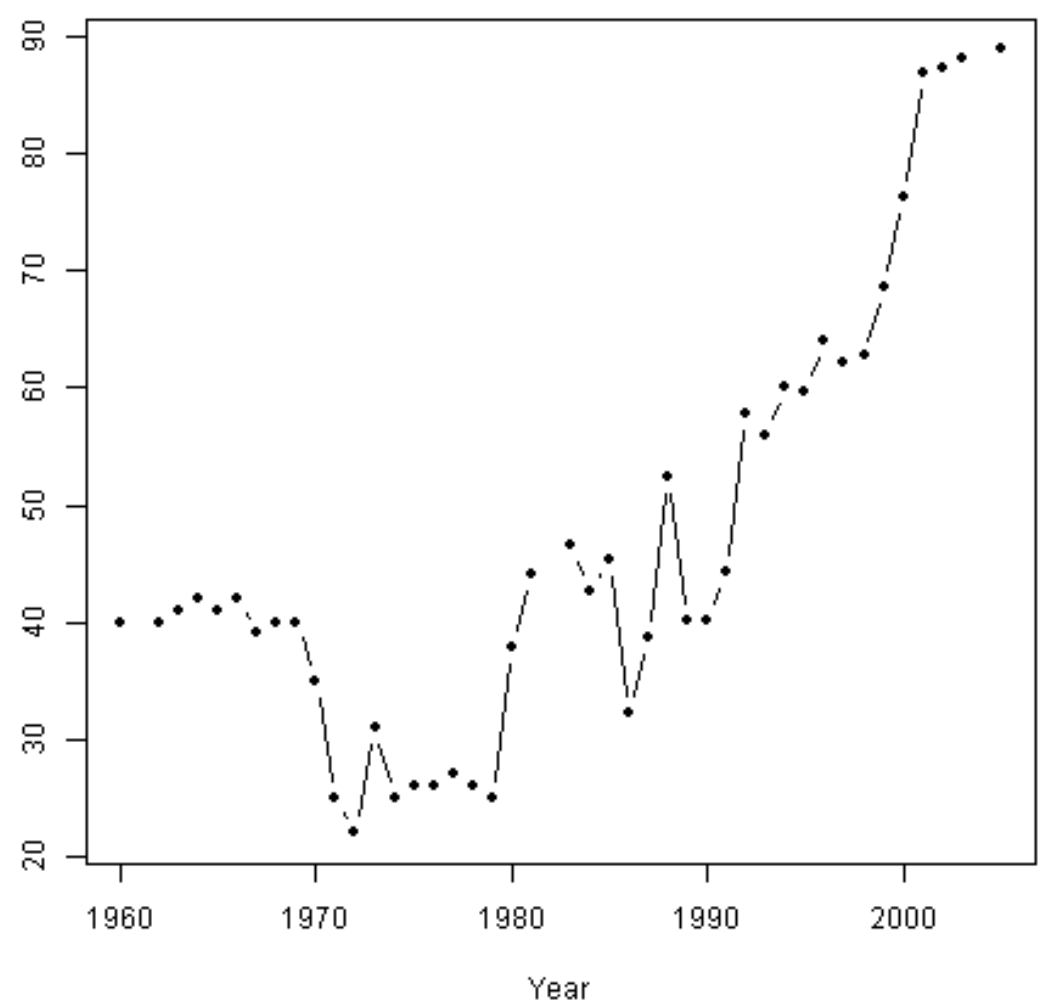

Figure 1: Promotion rates into secondary school

Note: Share of students in the last year of primary school promoted to secondary school. Sources: (Tarifa 1971) and annual statistical reports on primary education by the Tunisian Ministry of Education. 


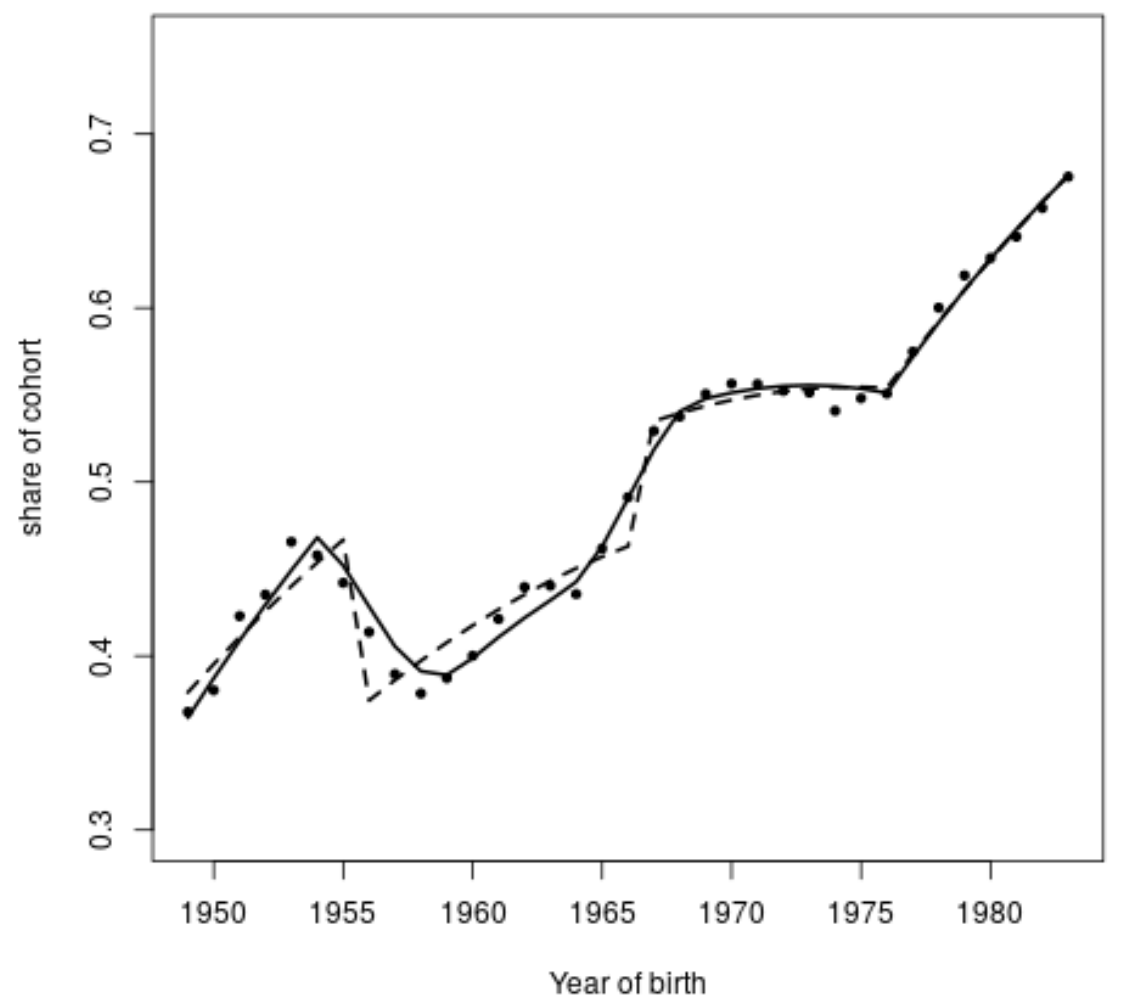

Figure 2: Illustration of the first stage: Attainment of secondary or university, by cohort

Note: Share of cohort attaining secondary or university education (i.e. with more than grade 6 of primary school). The line denotes the fitted values from a regression of such outcome on a 2nd order polynomial of birth year as well as the three instruments (1971 and 1980 jumps, and 1992 kink). The dashed line is a fitted regression that replaces the 1971 and the 1980 instruments by indicator functions of cohorts above the modal cohort among those exposed to the respective policy shift. 


\begin{tabular}{llllll}
\hline & Jump 1971 & Jump 1980 & Kink 1992 & All & N \\
\hline Demographics & & & & & \\
$\quad$ Year of birth & 1957 & 1966 & 1976 & 1968 & 1165670 \\
$\quad$ Age & 47.89 & 38.33 & 28.56 & 36.91 & 1165670 \\
Female & 0 & 0 & 0 & 0 & 1165670 \\
\hline Education & & & & & \\
$\quad$ No education & 0.18 & 0.11 & 0.06 & 0.11 & 1163065 \\
$\quad$ Primary & 0.44 & 0.42 & 0.37 & 0.4 & 1163065 \\
$\quad$ Secondary & 0.29 & 0.35 & 0.42 & 0.37 & 1163065 \\
$\quad$ University & 0.09 & 0.12 & 0.16 & 0.13 & 1163065 \\
$\quad$ Sec or Uni & 0.38 & 0.47 & 0.58 & 0.49 & 1163065 \\
$\quad$ Approx Grades Completed & 6.56 & 7.5 & 8.63 & 7.73 & 1163065 \\
\hline Employment & & & & & \\
$\quad$ Public employee & 0.26 & 0.22 & 0.13 & 0.19 & 1020817 \\
$\quad$ Skilled worker & 0.11 & 0.11 & 0.08 & 0.09 & 763108 \\
\hline Other info & & & & & \\
$\quad$ N & 434322 & 600212 & 599262 & 1165670 & \\
$\quad$ Range birth years & $1949-64$ & $1958-75$ & $1969-83$ & $1949-83$ & \\
$\quad$ Range ages & $39-60$ & $28-51$ & $20-40$ & $20-60$ & \\
\hline
\end{tabular}

Mean of variables used in the analysis for the different subsamples used as well as full sample. All variables except Age and Year of Birth are coded as zero-one variables.

Employment-related variables display a value zero (instead of missing) if the person is not employed. Skilled worker correspond to the categories of Professionals and Techinicians from the ILO ISCO-08 classification. The variable public employee are absent in the 2009 LFS while the variable skilled worker is only present in the 2004 census and the 2009 and 2010 labor force surveys, hence their small sample size.

Table 1: Summary statistics 


\begin{tabular}{|c|c|c|c|}
\hline & 1 & 2 & 3 \\
\hline \multicolumn{4}{|l|}{ Kink 1992} \\
\hline Secondary or University & $\begin{array}{l}0.022 \\
(0.002)^{* * *}\end{array}$ & $\begin{array}{l}0.021 \\
(0.003) * * *\end{array}$ & $\begin{array}{l}0.025 \\
(0.003)^{* * *}\end{array}$ \\
\hline University & $\begin{array}{l}0.009 \\
(0.002)^{* * *}\end{array}$ & $\begin{array}{l}0.01 \\
(0.003)^{* * *}\end{array}$ & $\begin{array}{l}0.01 \\
(0.005)^{* *}\end{array}$ \\
\hline Approx Grades Completed & $\begin{array}{l}0.175 \\
(0.022)^{* * *}\end{array}$ & $\begin{array}{l}0.198 \\
(0.032)^{* * *}\end{array}$ & $\begin{array}{l}0.192 \\
(0.04)^{* * *}\end{array}$ \\
\hline \multicolumn{4}{|l|}{ Jump 1980} \\
\hline Secondary or University & $\begin{array}{l}0.09 \\
(0.016)^{* * *}\end{array}$ & $\begin{array}{l}0.071 \\
(0.01)^{* * *}\end{array}$ & $\begin{array}{l}0.084 \\
(0.016)^{* * *}\end{array}$ \\
\hline University & $\begin{array}{l}0.032 \\
(0.006)^{* * *}\end{array}$ & $\begin{array}{l}0.027 \\
(0.004)^{* * *}\end{array}$ & $\begin{array}{l}0.041 \\
(0.008) * * *\end{array}$ \\
\hline Approx Grades Completed & $\begin{array}{l}0.797 \\
(0.113)^{* * *}\end{array}$ & $\begin{array}{l}0.608 \\
(0.081)^{* * *}\end{array}$ & $\begin{array}{l}0.845 \\
(0.127)^{* * *}\end{array}$ \\
\hline \multicolumn{4}{|l|}{ Jump 1971} \\
\hline Secondary or University & $\begin{array}{l}-0.178 \\
(0.017)^{* * *}\end{array}$ & $\begin{array}{l}-0.177 \\
(0.012)^{* * *}\end{array}$ & $\begin{array}{l}-0.179 \\
(0.024)^{* * *}\end{array}$ \\
\hline University & $\begin{array}{l}-0.024 \\
(0.012)^{* *}\end{array}$ & $\begin{array}{l}-0.033 \\
(0.007) * * *\end{array}$ & $\begin{array}{l}-0.026 \\
(0.011)^{* *}\end{array}$ \\
\hline Approx Grades Completed & $\begin{array}{l}-1.154 \\
(0.151)^{* * *}\end{array}$ & $\begin{array}{l}-1.351 \\
(0.126)^{* * *}\end{array}$ & $\begin{array}{l}-1.229 \\
(0.207)^{* * *}\end{array}$ \\
\hline Polynomial order & 1 & 2 & 1 \\
\hline Bandwidth & 4 & 7 & 4 \\
\hline years & 2004_10 & $2004 \_10$ & $2007 \_10$ \\
\hline $\mathrm{N}$ & 70 & 111 & 40 \\
\hline
\end{tabular}

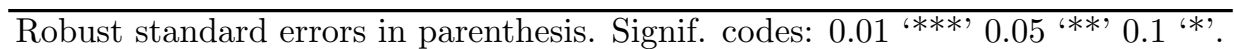

Standarad errors clustered at the birth year level. Coefficients from separate regressions of the education outcome in each row on year fixed effects, age fixed effects, a function of birth year and a variable capturing the respective discontinuity, for which the coefficient is shown. The variable Approx Grades completed is a attributes to each education level its corresponding mean grades completed estimated from the 2010 LFS. Each row panel corresponds to a different policy reform, the 1992 kink, and the 1980 and 1971 jumps. Each regression uses a window of birth years centered at the birth year affected by the corresponding jump/ kink. The row bandwith refers to the number of birth years of the corresponding window. The row polynomial order refers to the order of the birth year polynomial. The row years indicates the survey years use in the specification, either all of them (2004-10) or only the latest years (2007-10), where effects are identified for older individuals.

Table 2: First Stage Results 


\begin{tabular}{llll}
\hline & \multicolumn{1}{c}{1} & \multicolumn{1}{c}{2} & \multicolumn{1}{c}{3} \\
\hline Public employee & & & \\
Kink 1992 & 0.008 & 0.005 & 0.009 \\
& $(0.001)^{* * *}$ & $(0.003)^{*}$ & $(0.002)^{* * *}$ \\
Jump 1980 & 0.033 & 0.027 & 0.034 \\
& $(0.007)^{* * *}$ & $(0.004)^{* * *}$ & $(0.013)^{* *}$ \\
Jump 1971 & -0.074 & -0.081 & -0.074 \\
& $(0.018)^{* * *}$ & $(0.007)^{* * *}$ & $(0.022)^{* * *}$ \\
\hline
\end{tabular}

\begin{tabular}{lll}
\hline Skilled occupation & & \\
Kink 1992 & 0.002 & -0.001 \\
& $(0.001)$ & $(0.004)$ \\
Jump 1980 & 0.012 & -0.002 \\
& $(0.012)$ & $(0.007)$ \\
Jump 1971 & -0.049 & -0.02 \\
& $(0.02)^{* *}$ & $(0.007)^{* * *}$ \\
\hline
\end{tabular}

$\begin{array}{llll}\text { Polynomial order } & 1 & 2 & 1 \\ \text { Bandwidth } & 4 & 7 & 4 \\ \text { years } & 2004 \_10 & 2004 \_10 & 2007 \_10\end{array}$

Robust standard errors in parenthesis. Signif. codes: $0.01^{(* * *)} 0.05^{(* *)} 0.1$ (*).

Standarad errors clustered at the birth year level. Coefficients are from separate regressions of the outcome in each row panel on year fixed effects, age fixed effects, a function of birth year and a variable capturing the respective discontinuity, for which the coefficient is shown in each row. Each regression uses a window of birth years centered at the birth year affected by the corresponding jump/ kink. The row bandwith refers to the number of birth years of the corresponding window. The row polynomial order refers to the order of the birth year polynomial. The row years indicates the survey years use in the specification, either all of them (2004-10) or only the latest years (2007-10), where effects are identified for older individuals.

Table 3: Education and desirable jobs, different cohorts. Reduced form results 


\begin{tabular}{|c|c|c|c|c|}
\hline & 1 & 2 & 3 & 4 \\
\hline \multicolumn{5}{|l|}{ Public employee } \\
\hline Kink 1992 & $\begin{array}{l}0.022 \\
(0.003) * * *\end{array}$ & $\begin{array}{l}0.044 \\
(0.006)^{* * *}\end{array}$ & $\begin{array}{l}0.025 \\
(0.01)^{* *}\end{array}$ & $\begin{array}{l}0.042 \\
(0.013)^{* *}\end{array}$ \\
\hline \multirow[t]{2}{*}{ Jump 1980} & 0.037 & 0.027 & 0.039 & 0.038 \\
\hline & $(0.001)^{* * *}$ & $(0.01)^{* *}$ & $(0.007)^{* * *}$ & $(0.012)^{* * *}$ \\
\hline \multirow[t]{2}{*}{ Jump 1971} & 0.037 & 0.071 & 0.06 & 0.063 \\
\hline & $(0)^{* * *}$ & $(0.009)^{* * *}$ & $(0.006)^{* * *}$ & $(0.014)^{* * *}$ \\
\hline diff_92_71 & -0.015 & -0.027 & -0.035 & -0.021 \\
\hline p_value_diff & 0 & 0.012 & 0.003 & 0.266 \\
\hline \multicolumn{5}{|l|}{ Skilled occupation } \\
\hline Kink 1992 & $\begin{array}{l}0.026 \\
(0.002)^{* * *}\end{array}$ & $\begin{array}{l}0.009 \\
(0.004)^{*}\end{array}$ & $\begin{array}{l}-0.007 \\
(0.033)\end{array}$ & \\
\hline Jump 1980 & $\begin{array}{l}0.034 \\
(0.002) * * *\end{array}$ & $\begin{array}{l}0.019 \\
(0.017)\end{array}$ & $\begin{array}{l}0.003 \\
(0.007)\end{array}$ & \\
\hline Jump 1971 & $\begin{array}{l}0.034 \\
(0.001)^{* * *}\end{array}$ & $\begin{array}{l}0.035 \\
(0.01)^{* * *}\end{array}$ & $\begin{array}{l}0.016 \\
(0.004) * * *\end{array}$ & \\
\hline diff_92_71 & -0.008 & -0.026 & -0.022 & \\
\hline p_value_diff & 0.001 & 0.031 & 0.469 & \\
\hline \multirow{4}{*}{$\begin{array}{l}\text { Estimator } \\
\text { Polynomial order } \\
\text { Bandwidth } \\
\text { years }\end{array}$} & OLS & IV & IV & IV \\
\hline & 1 & 1 & 2 & 1 \\
\hline & 1 & 4 & 7 & 4 \\
\hline & $2004 \_10$ & 2004_10 & $2004 \_10$ & 2007_10 \\
\hline \multicolumn{5}{|c|}{$\begin{array}{l}\text { Robust standard errors in parenthesis. Signif. codes: } 0.01 \text { (***) } 0.05^{(* *)} 0.1^{(*)} \text {. } \\
\text { Standarad errors clustered at the birth year level. Coefficients are from separate } \\
\text { regressions of the outcome in each row panel on year fixed effects, age fixed effects, a } \\
\text { function of birth year and approximate grades completed, using as instrument a } \\
\text { variable capturing the policy reform in each row in the columns using an IV estimator. } \\
\text { Each regression uses a window of birth years centered at the birth year affected by the } \\
\text { corresponding jump/ kink. The last two rows of each panel correspond to the } \\
\text { difference between the } 1992 \text { Kink coefficient and the } 1971 \text { Jump coefficient, and the } \\
\text { p-value of this difference, respectively. The row bandwith refers to the number of birth } \\
\text { years of the corresponding window. The row polynomial order refers to the order of } \\
\text { the birth year polynomial. The row years indicates the survey years use in the } \\
\text { specification, either all of them (2004-10) or only the latest years }(2007-10) \text {, where } \\
\text { effects are identified for older individuals. }\end{array}$} \\
\hline
\end{tabular}

Table 4: Education and desirable jobs, different cohorts. IV results 


\section{On-line Appendix}

\section{Public sector employment: shares and OLS estimates of returns to education by age}
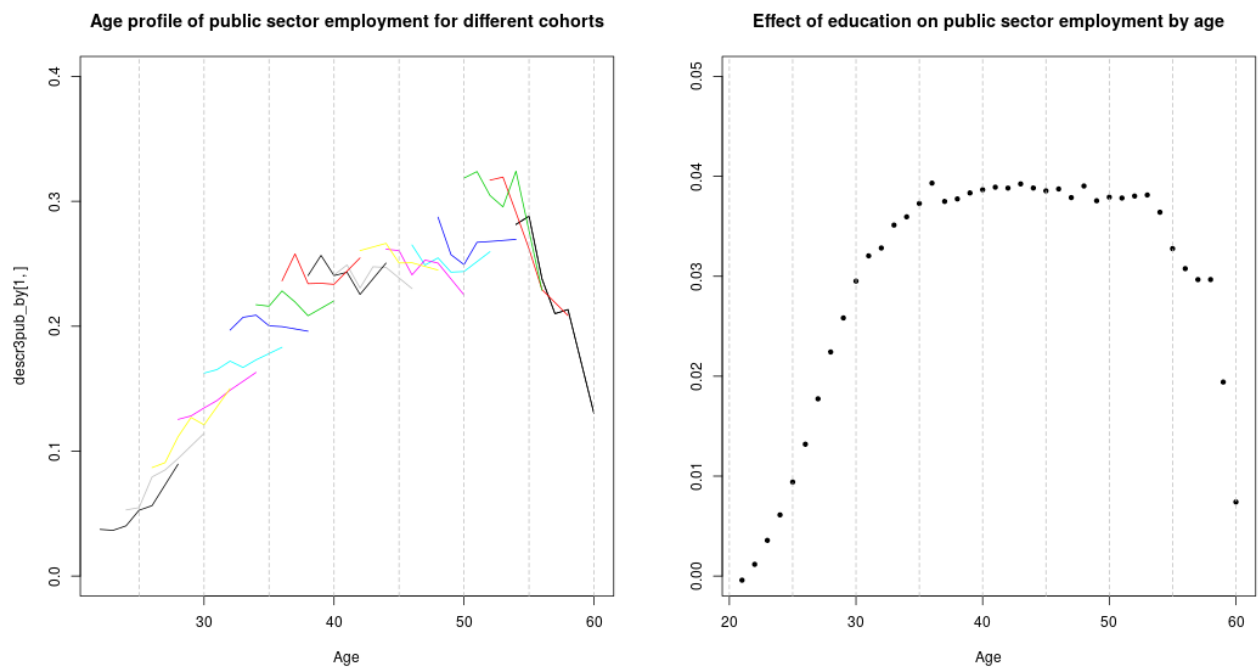

Figure A1: Public sector employment: shares and OLS estimates of returns to education by age

Note: Life-cycle pattern of public sector employment (left panel) and of returns to education in terms of public sector employment (right panel). The left panel traces the share of public sector employment of cohorts born 2 years apart as they age. the right panel plots the coefficients of an OLS regression of public sector employment on survey year dummies, and age dummies interacted with years of education; the coefficients plotted are the uninteracted years of education coefficient plus those of the age-education interactions. 


\section{Illustration of reduced form for public sector employ- ment}

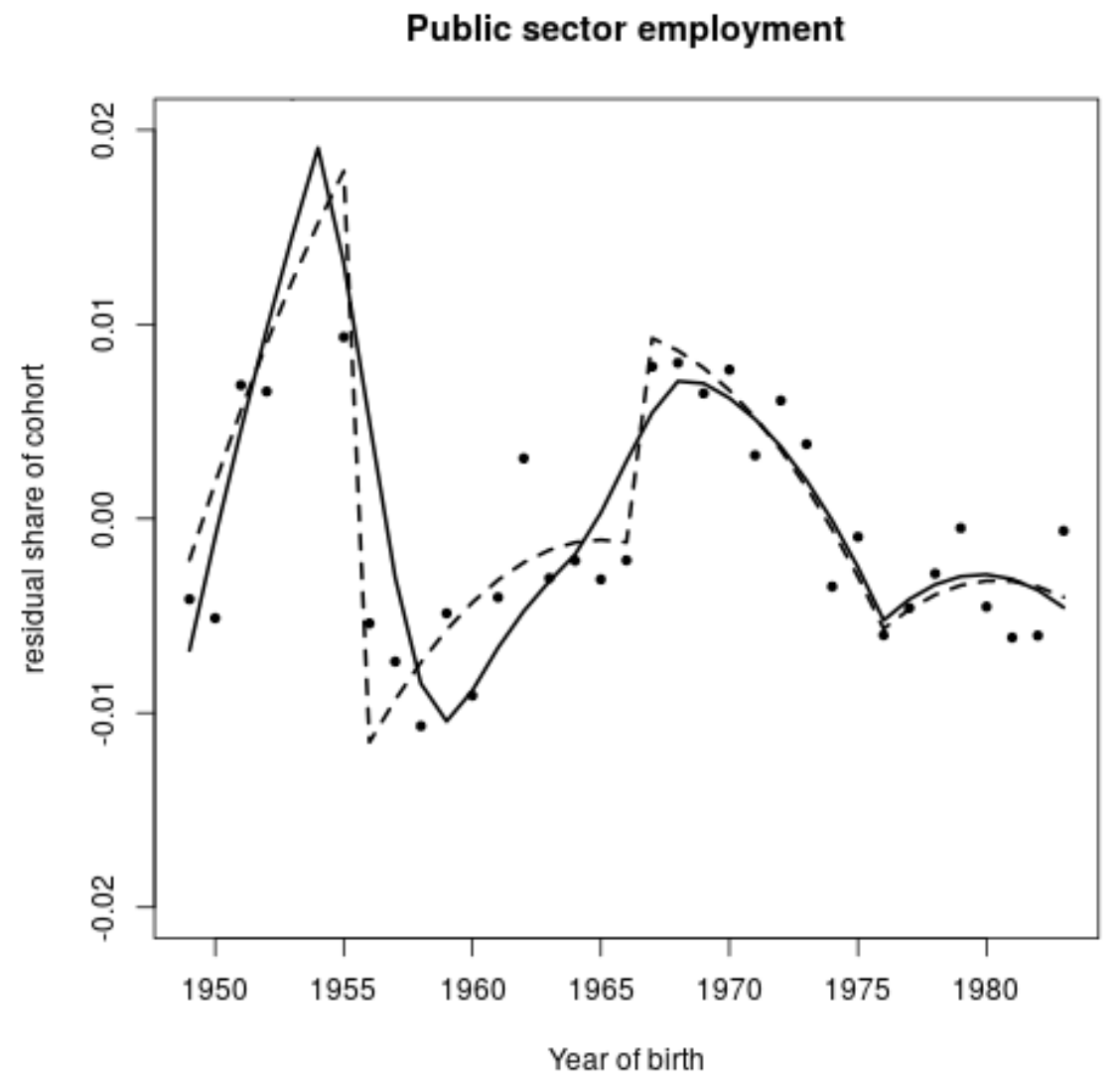

Figure A2: Illustration of reduced form for public sector employment, using all policy changes

Graphical depiction of the reduced form of public sector employment. Dots show residuals from regressions of public sector employment on year and age fixed effects, as a function of year of birth. The line denotes the fitted values from a regression of such residuals on a 2nd order polynomial of birth year as well as the three instruments (1971 and 1980 jumps, and 1992 kink). The dashed line is a fitted regression that replaces the 1971 and the 1980 instruments by indicator functions of cohorts above the modal cohort among those exposed to the respective policy shift. 


\section{Potential confounders: Share of individuals with no formal education}

\begin{tabular}{llll}
\hline \multicolumn{1}{c}{1} & \multicolumn{1}{c}{2} & \multicolumn{1}{c}{3} \\
\hline $\begin{array}{l}\text { Kink 1992 } \\
\text { No Education }\end{array}$ & $\begin{array}{l}0.001 \\
(0.001)\end{array}$ & $\begin{array}{l}-0.003 \\
(0.001)^{* *}\end{array}$ & $\begin{array}{l}0.002 \\
(0.001)\end{array}$ \\
\hline Jump 1980 & & & \\
No Education & -0.02 & -0.009 & -0.026 \\
& $(0.004)^{* * * *}$ & $(0.005)^{*}$ & $(0.009)^{* *}$ \\
\hline Jump 1971 & & & \\
No Education & 0.003 & 0.033 & 0.013 \\
& $(0.016)$ & $(0.009)^{* * *}$ & $(0.025)$ \\
\hline & & & \\
Polynomial order & 1 & 2 & 1 \\
Bandwidth & 4 & 7 & 4 \\
years & $2004 \_10$ & $2004 \_10$ & $2007 \_10$ \\
N & 70 & 111 & 40
\end{tabular}

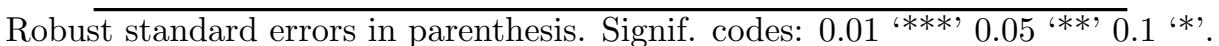

Standarad errors clustered at the birth year level. Coefficients from separate regressions of no education on year fixed effects, age fixed effects, a function of birth year and a variable capturing the respective discontinuity, for which the coefficient is shown. Each row panel corresponds to a different policy reform, the $1992 \mathrm{kink}$, and the 1980 and 1971 jumps. Each regression uses a window of birth years centered at the birth year affected by the corresponding jump/ kink. The row bandwith refers to the number of birth years of the corresponding window. The row polynomial order refers to the order of the birth year polynomial. The row years indicates the survey years use in the specification, either all of them (2004-10) or only the latest years (2007-10), where effects are identified for older individuals.

Table A1: Placebo with no education as outcome variable 


\section{IV results, controlling for no education}

\begin{tabular}{|c|c|c|c|c|}
\hline & 1 & 2 & 3 & 4 \\
\hline \multicolumn{5}{|l|}{ Public employee } \\
\hline Kink 1992 & $\begin{array}{l}0.025 \\
(0.003) * * *\end{array}$ & $\begin{array}{l}0.04 \\
(0.005)^{* * *}\end{array}$ & $\begin{array}{l}0.03 \\
(0.012)^{* *}\end{array}$ & $\begin{array}{l}0.043 \\
(0.013)^{* *}\end{array}$ \\
\hline Jump 1980 & $\begin{array}{l}0.044 \\
(0.001)^{* * *}\end{array}$ & $\begin{array}{l}0.057 \\
(0.012)^{* * *}\end{array}$ & $\begin{array}{l}0.052 \\
(0.006)^{* * *}\end{array}$ & $\begin{array}{l}0.051 \\
(0.019)^{* *}\end{array}$ \\
\hline Jump 1971 & $\begin{array}{l}0.043 \\
(0)^{* * *}\end{array}$ & $\begin{array}{l}0.072 \\
(0.01)^{* * *}\end{array}$ & $\begin{array}{l}0.063 \\
(0.006)^{* * *}\end{array}$ & $\begin{array}{l}0.065 \\
(0.013) * * *\end{array}$ \\
\hline diff_92_71 & -0.018 & -0.032 & -0.033 & -0.021 \\
\hline p_value_diff & 0 & 0.005 & 0.011 & 0.242 \\
\hline \multicolumn{5}{|l|}{ Skilled occupation } \\
\hline Kink 1992 & $\begin{array}{l}0.031 \\
(0.003)^{* * *}\end{array}$ & $\begin{array}{l}0.011 \\
(0.009)\end{array}$ & $\begin{array}{l}-0.015 \\
(0.047)\end{array}$ & \\
\hline Jump 1980 & $\begin{array}{l}0.045 \\
(0.002)^{* * *}\end{array}$ & $\begin{array}{l}0.015 \\
(0.012)\end{array}$ & $\begin{array}{l}-0.008 \\
(0.013)\end{array}$ & \\
\hline Jump 1971 & $\begin{array}{l}0.044 \\
(0.001)^{* * *}\end{array}$ & $\begin{array}{l}0.04 \\
(0.008) * * *\end{array}$ & $\begin{array}{l}0.011 \\
(0.005)^{*}\end{array}$ & \\
\hline diff_92_71 & -0.014 & -0.029 & -0.026 & \\
\hline p_value_diff & 0 & 0.028 & 0.554 & \\
\hline Estimator & OLS & IV & IV & IV \\
\hline Polynomial order & 1 & 1 & 2 & 1 \\
\hline Bandwidth & 1 & 4 & 7 & 4 \\
\hline years & $2004 \_10$ & $2004 \_10$ & $2004 \_10$ & $2007 \_10$ \\
\hline
\end{tabular}

Robust standard errors in parenthesis. Signif. codes: $0.01^{\text {(***) }} 0.05^{\text {(**) }} 0.1^{\text {(*). }}$.

Standarad errors clustered at the birth year level. Coefficients are from separate regressions of the outcome in each row panel on year fixed effects, age fixed effects, a function of birth year, the share of individuals with no education, and approximate grades completed, using as instrument a variable capturing the policy reform in each row in the columns using an IV estimator. Each regression uses a window of birth years centered at the birth year affected by the corresponding jump/ kink. The last two rows of each panel correspond to the difference between the 1992 Kink coefficient and the 1971 Jump coefficient, and the p-value of this difference, respectively. The row bandwith refers to the number of birth years of the corresponding window. The row polynomial order refers to the order of the birth year polynomial. The row years indicates the survey years use in the specification, either all of them (2004-10) or only the latest years (2007-10), where effects are identified for older individuals.

Table A2: IV results, controlling for no education 


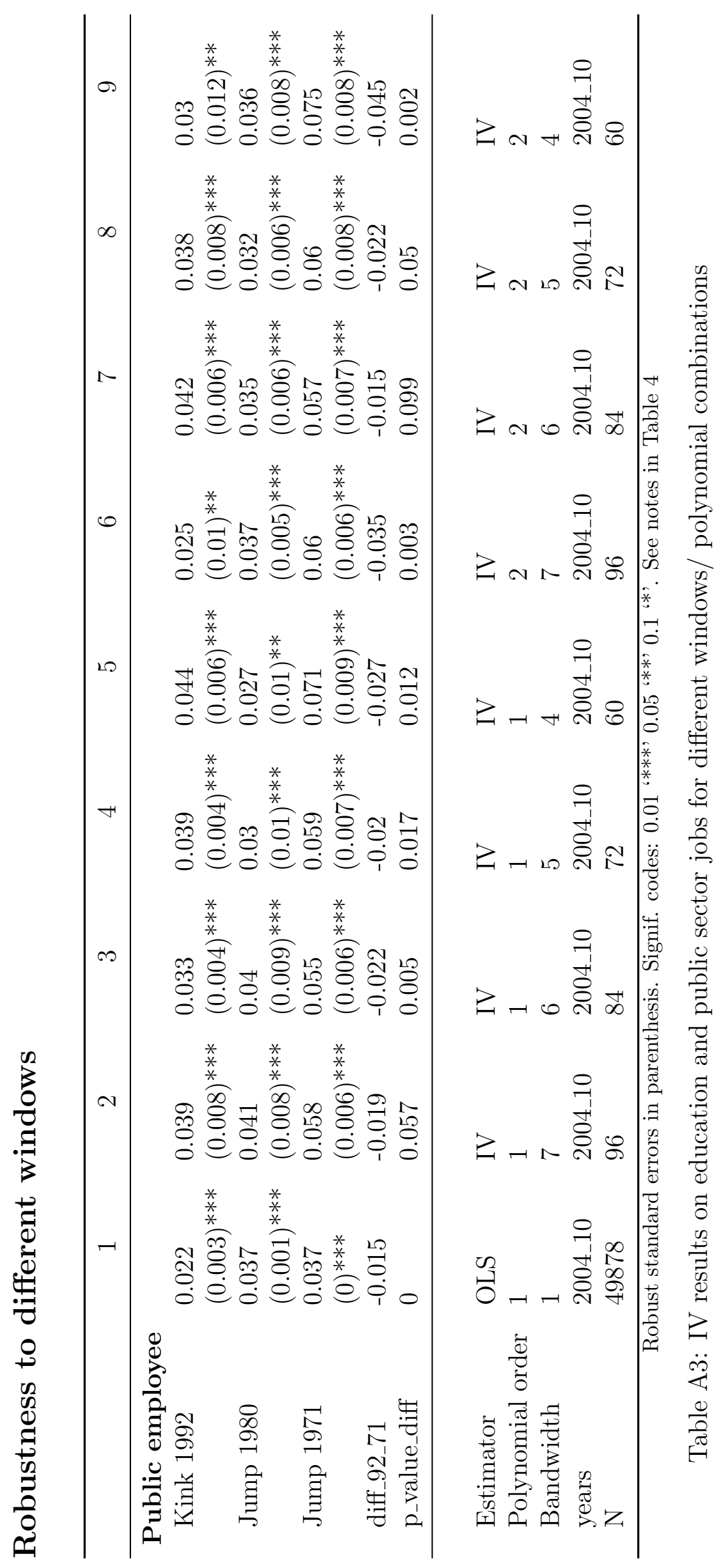




\section{Robustness to absence of survey weights}

\begin{tabular}{|c|c|c|c|c|}
\hline & 1 & 2 & 3 & 4 \\
\hline \multicolumn{5}{|l|}{ Public employee } \\
\hline Kink 1992 & $\begin{array}{l}0.022 \\
(0.003)^{* * *}\end{array}$ & $\begin{array}{l}0.04 \\
(0.003)^{* * *}\end{array}$ & $\begin{array}{l}0.022 \\
(0.008) * * *\end{array}$ & $\begin{array}{l}0.039 \\
(0.01)^{* * *}\end{array}$ \\
\hline Jump 1980 & $\begin{array}{l}0.037 \\
(0.001) * * *\end{array}$ & $\begin{array}{l}0.024 \\
(0.01)^{* *}\end{array}$ & $\begin{array}{l}0.041 \\
(0.006)^{* * *}\end{array}$ & $\begin{array}{l}0.035 \\
(0.008) * * *\end{array}$ \\
\hline Jump 1971 & $\begin{array}{l}0.037 \\
(0)^{* * *}\end{array}$ & $\begin{array}{l}0.072 \\
(0.009)^{* * *}\end{array}$ & $\begin{array}{l}0.059 \\
(0.006) * * *\end{array}$ & $\begin{array}{l}0.057 \\
(0.011)^{* * *}\end{array}$ \\
\hline diff_92_71 & -0.015 & -0.031 & -0.037 & -0.019 \\
\hline p_value_diff & 0 & 0.001 & 0 & 0.205 \\
\hline \multicolumn{5}{|l|}{ Skilled occupation } \\
\hline Kink 1992 & $\begin{array}{l}0.026 \\
(0.002)^{* * *}\end{array}$ & $\begin{array}{l}-0.005 \\
(0.01)\end{array}$ & $\begin{array}{l}-0.021 \\
(0.026)\end{array}$ & \\
\hline Jump 1980 & $\begin{array}{l}0.034 \\
(0.002)^{* * *}\end{array}$ & $\begin{array}{l}0.018 \\
(0.015)\end{array}$ & $\begin{array}{l}0.006 \\
(0.006)\end{array}$ & \\
\hline Jump 1971 & $\begin{array}{l}0.034 \\
(0.001)^{* * *}\end{array}$ & $\begin{array}{l}0.034 \\
(0.009) * * *\end{array}$ & $\begin{array}{l}0.017 \\
(0.003) * * *\end{array}$ & \\
\hline diff_92_71 & -0.008 & -0.04 & -0.038 & \\
\hline p_value_diff & 0.001 & 0.005 & 0.13 & \\
\hline Estimator & OLS & IV & IV & IV \\
\hline Polynomial order & 1 & 1 & 2 & 1 \\
\hline Bandwidth & 1 & 4 & 7 & 4 \\
\hline years & $2004 \_10$ & $2004 \_10$ & $2004 \_10$ & 2007_10 \\
\hline
\end{tabular}

Robust standard errors in parenthesis. Signif. codes: $0.01^{\text {(***) }} 0.05^{\text {(**) }} 0.1^{\text {(*). }}$.

Standarad errors clustered at the birth year level. Coefficients are from separate regressions of the outcome in each row panel on year fixed effects, age fixed effects, a

function of birth year and approximate grades completed, using as instrument a variable capturing the policy reform in each row in the columns using an IV estimator. Observations are aggregated without the use of survey weights. Each regression uses a window of birth years centered at the birth year affected by the corresponding jump/ kink. The last two rows of each panel correspond to the difference between the 1992

Kink coefficient and the 1971 Jump coefficient, and the p-value of this difference, respectively. The row bandwith refers to the number of birth years of the corresponding window. The row polynomial order refers to the order of the birth year polynomial. The row years indicates the survey years use in the specification, either all of them (2004-10) or only the latest years (2007-10), where effects are identified for older individuals.

Table A4: IV results with no survey weights 